\title{
Um diálogo entre a Educação Ambiental e a Ciência por meio do filme "Sonhos Tropicais": Uma contribuição para a formação inicial de professores.
}

A dialogue between Environmental Education and Science through the film "Tropical Dreams ": A contribution to the initial formation of teachers

Un diálogo entre Educación Ambiental y Ciencia a través de la película "Sueños tropicales ": Una contribución a la formación inicial de professor

\author{
Andressa Aparecida Castro \\ Graduanda, UFLA,Brasil \\ andressaprcastro@gmail.com \\ Rosângela Alves Tristão Borém \\ Professora Doutora, UFLA, Brasil \\ tristãoborem@gmail.com \\ Laise Vieira Gonçalves \\ Professora Mestre, UFLA, Brasil \\ laisebiologa@gmail.com \\ Antonio Fernandes Nascimento Júnior \\ Professor Doutor, UFLA,Brasil \\ Toni_nascimento@yahoo.com.br
}




\section{RESUMO}

A formação inicial de professores precisa ser repensa, é necessário que os licenciados em formação contemplem não só os conteúdos mas também as práticas metodológicas, buscando promover a educação como uma prática social, atuando na formação de cidadãos críticos, reflexivos e transformadores que compreendam o meio em que estão inserido, para assim, transforma-lo. Diante desta questão o presente trabalho tem como objetivo demonstrar o diálogo entre a educação ambiental e a ciência a partir do filme brasileiro: "Sonho Tropical" dirigido por André Sturm e estreou comercialmente no Brasil em 2002, o filme retrata a situação do Rio de Janeiro, mostrando um ambiente influenciado tanto por questões socais, politicas, econômicas, sociais e outras. Para analise dos resultados, utilizou-se a pesquisa qualitativa, por meio da categorização temática. Como resultado foi obtido três categorias: "a ciência procura meios para erradicar problemas", "saneamento básico" e "o ser humano altera o meio ambiente", estas categorias mostram como é necessário que a educação ambiental seja trabalhada através de um processo continuo, para quebrar o conceito conservacionista de meio ambiente, e como o cinema auxilia nesta construção do conceito, o que evidencia a necessidade de se apropriar destes conceitos para formação inicial de professores críticos transformadores.

PALAVRAS-CHAVE: Educação Ambiental, Arte, Formação de professores

\section{ABSTRACT}

The initial training of teachers needs to be rethought, it is necessary that the graduates in formation contemplate not only the contents but also the methodological practices, seeking to promote education as a social practice, acting in the formation of critical, reflexive and transforming citizens who understand the medium in which they are inserted, in order to transform it. In view of this issue the present work aims to demonstrate the dialogue between environmental education and science from the Brazilian film "Tropical Dream" directed by André Sturm and commercially debuted in Brazil in 2002, the film portrays the situation of Rio showing an environment influenced by social, political, economic, social and other issues. To analyze the results, qualitative research was used, through thematic categorization. As a result, three categories have been obtained: " science seeks means to eradicate problems ", " basic sanitation " and " human beings alter the environment ", these categories show how environmental education needs to be worked on through a continuous process, to break the conservationist concept of the environment, and how cinema helps in this construction of the concept, which evidences the need to appropriate these concepts for the initial formation of transforming critical teachers.

KEY WORDS: Environmental Education, Art, Teacher Training.

\section{RESUMEN}

La formación inicial de profesores necesita ser repensada, es necesario que los licenciados en formación contemplen no sólo los contenidos, sino también las prácticas metodológicas, buscando promover la educación como una práctica social, actuando en la formación de ciudadanos críticos, reflexivos y transformadores que comprendan el medio en el que están insertados, para así, transformarlo. En este sentido, el presente trabajo tiene como objetivo demostrar el diálogo entre la educación ambiental y la ciencia a partir de la película brasileña: " Sueño Tropical " dirigido por André Sturm y estrenado comercialmente en Brasil en 2002, la película retrata la situación de Río de enero, mostrando un ambiente influenciado tanto por cuestiones sociales, políticas, económicas, sociales y otras. Para el análisis de los resultados, se utilizó la investigación cualitativa, por medio de la categorización temática. Como resultado se obtienen tres categorías: "la ciencia busca medios para erradicar problemas", "saneamiento básico" y "el ser humano altera el medio ambiente", estas categorías muestran cómo es necesario que la educación ambiental sea trabajada a través de un proceso continuo, para romper el concepto conservacionista de medio ambiente, y cómo el cine auxilia en esta construcción del concepto, lo que evidencia la necesidad de apropiarse de estos conceptos para la formación inicial de profesores críticos transformadores.

PALABRAS CLAVE: Educación Ambiental, Arte, Formación de Profesores 


\section{INTRODUÇÃO}

O conceito de meio ambiente é caracterizado pela explicitação de convergências e divergências, todas estes conceitos e teorias explicam diferentemente a relação do meio ambiente com o homem, neste sentido cada uma dessas abordagens são construídas a partir da forma de se interpretar a relação entre a natureza e o homem, desde o seu sentido naturalista, enxergando o ambiente apenas em seu sentido biológico á abordagem do ambiente como um todo que é influenciado e modificado por questões sociais, politicas, econômicas, culturais, entre outras.

“Em 1972, em Estocolmo, a Conferência das Nações Unidas sobre o Meio Ambiente define o meio ambiente como: o conjunto de componentes físicos, químicos, biológicos e sociais capazes de causar efeitos diretos ou indiretos, em um prazo curto ou longo, sobre os seres vivos e as atividades humanas."

Já a Política Nacional do Meio Ambiente (PNMA) brasileira, estabelecida pela Lei 6938 de 1981, define meio ambiente como "o conjunto de condições, leis, influências e interações de ordem física, química e biológica, que permite, abriga e rege a vida em todas as suas formas".

Outra vertente da definição de meio ambiente é a que provem da educação ambiental crítica, que é uma práxis social e tem objetivo de emancipação do sujeito e buscando a sua transformação por meio da compreensão da realidade de maneira completa, não fragmentada (LOUREIRO, TOZONI-REIS, 2007).

Esta última vertente será utilizada neste trabalho, a fim de compreender o ser humano e suas relações com o meio em que está situado. A educação ambiental crítica então permite compreender e analisar essa relação entre o homem, o ambiente e a sociedade. (CÂNDIDO, 2017)

Em consonância com estas ideias, entende-se que para compreender a realidade como um todo é preciso que o contexto social seja levado em conta, neste sentido a utilização de recursos metodológicos alternativos é um caminho para esta compreensão, como o uso do cinema, que tem um grande potencial para a formação de cidadãos críticos, reflexivos e transformadores, uma vez que através do cinema é possível trabalhar a imaginação, sensibilidade, criatividade, além de conseguir reconhecer diferentes realidades, entre outras coisas (CABRESA, 2006).

A linguagem cinematográfica dialoga com uma visão filosófica, podendo então definir três categorias nos filmes. A primeira demonstra a capacidade do cinema de mostrar realidade não só de maneira racional, mas também efetiva ao mesmo tempo. A segunda trata a potencialidade do cinema de sensibilizar o expectador, despertando a sensibilidade do mesmo. Por ultimo, a terceira categoria trás o cinema como um caminho para compreender realidades distintas (CABRESA, 2006).

"Sonhos Tropicais" filme dirigido por André Sturm, estreou comercialmente no Brasil em 2002. No filme é possível perceber a situação contemporânea do Brasil, que apesar do filme retratar a realidade da cidade do Rio de Janeiro no início do séc. XX, ainda trás muitos aspectos e elementos comuns, que estão presente na atual conjuntura da sociedade brasileira. 
A historia do filme é contado a partir da realidade vivida no Rio de Janeiro e se inicia no ano de 1899, em um Brasil marcado pela crise no café, que nessa época era a principal riqueza brasileira.

Em 1899 a cidade do Rio de Janeiro vivia uma situação precária, onde a cidade não possuía um sistema hidrossanitário para atender a população, assim a proliferação de doenças aumentava, facilitando o desenvolvimento de animais vetores, como: ratos, insetos, entre outros. Além da falta de saneamento básico, havia outros aspectos que influenciavam o ambiente daquela época, como a falta de hospitais na cidade para atender uma alta demanda de pessoas infectadas por doenças, decorrentes da falta de saneamento básico, apontando falhas na saúde publica.

Além das doenças decorrentes da falta de saneamento básico, ainda existiam as doenças sexualmente transmissíveis, consequência do trafico de mulheres, trazidas da Europa para o Brasil. Outro aspecto de destaque no filme são as moradias. Naquele tempo, havia muitos cortiços, que eram caracterizados por serem moradias coletivas onde residia a população pobre e não possuíam condições mínimas de higiene e saúde, tanto pessoal quanto coletiva.

O filme também aborda a chegada da peste em São Paulo e o desenvolvimento da vacina para o combate da febre amarela e da varíola, tendo como um de seus pesquisadores o médico Oswaldo Cruz. Além do desenvolvimento da vacina, Oswaldo Cruz também promoveu ações preventivas contra os vetores das mesmas doenças, a fim de diminuir os casos de doença. Como houve uma rejeição popular em relação às vacinas, os governantes determinaram que a vacina fosse obrigatória, o que causou a revolta da vacina.

O filme não simplifica nem contorna as condições econômicas, sociais, culturais politicas e econômicas do Brasil naquela época, mostrando a complexidade da influência dessa conjuntura na vida da população.

Neste cenário, o então presidente Rodrigues Alves estabelece três medidas para tentar mudar este contexto. A primeira é a nomeando o medico Oswaldo Cruz para assumir a diretoria da Saúde Pública, com o intuito de acabar com as doenças que atingiam a população. A segunda foi à luta contra a peste bubônica, as duas medidas tinham como estratégia a utilização de campanhas para conscientizar, alertar e prevenir a população. Por fim, a terceira medida era a regulamentação da lei que tornava obrigatório a utilização de vacinas contra os surtos de varíola, medida está que mais tarde, marcada por uma revolta da população, daria origem a "Revolta da Vacina" que será descrita posteriormente.

Marcado por uma série de denúncias o Rio de Janeiro naquela época é regido por diversos acontecimentos, que ainda estão presente na realidade brasileira. No final do século XX o Brasil é marcado pela crise no café, que naquele contexto era a principal riqueza brasileira, que juntamente com a grande quantidade de epidemias levou a cidade do Rio de Janeiro a ficar conhecida como: "a cidade fedorenta", trazendo como uma das consequências o declínio nas exportações e econômica brasileira, uma vez que neste cenário, os navios evitavam o contato com os portos do Rio de Janeiro, alegando a alta possibilidade dos tripulantes se contaminarem com as doenças.

Estes acontecimentos juntamente com outros ocorridos naquela época demonstram como a falta de saneamento básico, falta de hospitais públicos, fatores políticos e econômicos influenciam na sociedade e no ambiente que a mesma vive. 
Nessa perspectiva, a obra também retrata diversos aspectos ambientais que permitem relacionar as questões politicas, sociais, culturais, econômicas. Elementos estes que contribuem para um maior entendimento da realidade de forma mais ampla e não fragmentada, tendo como base um olhar crítico do modelo de sociedade em que estamos inseridos, quebrando assim o olhar tradicional para sociedade, que analisa a relação do sujeito apenas individualmente com a natureza. (LOUREIRO, TOZONI-REIS, 2007).

\section{METODOLOGIA}

Este estudo consiste em uma análise realizada a partir da atividade desenvolvida pelos alunos do terceiro período do curso de Ciências Biológicas na Universidade Federal de Lavras (UFLA), através da disciplina "Metodologia Cientifica" que é obrigatória para os alunos da modalidade bacharel. A atividade foi aplicada para vinte e nove alunos, sendo perguntada a seguinte questão: "Qual a relação do filme sonhos tropicais com o meio ambiente e a ciência.

Neste sentido, para a análise das falas, foi utilizada a análise de conteúdos e categorização das falas dos participantes (MINAYO e colaboradores, 2008).

\section{RESULTADOS E DISCUSSÃO}

A partir das análises das falas foram elaboradas três categorias.

\section{Quadro 1: Categorias}

\begin{tabular}{|c|c|c|c|}
\hline Categoria & Descrição & Frequência & Ocorrência \\
\hline $\begin{array}{l}\text { A ciência procura } \\
\text { meios para } \\
\text { erradicar } \\
\text { problemas }\end{array}$ & $\begin{array}{l}\text { Aqui se concentram as falas que } \\
\text { remetem a ciência ao ponto de vista } \\
\text { positivo caracterizada pela busca de } \\
\text { desenvolvimento tecnológico, de } \\
\text { modo a desprezar os desvios que } \\
\text { ocorrem. }\end{array}$ & 22 & 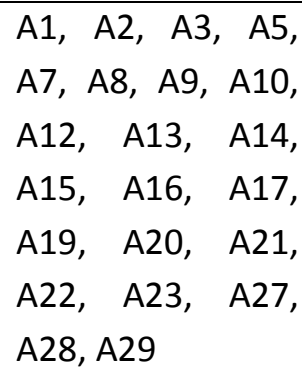 \\
\hline $\begin{array}{l}\text { Saneamento } \\
\text { básico }\end{array}$ & $\begin{array}{l}\text { Nesta categoria a falta de } \\
\text { saneamento básico esta relacionada } \\
\text { diretamente com a proliferação de } \\
\text { doenças. }\end{array}$ & 16 & $\begin{array}{l}\text { A3, A4, A8, A9, } \\
\text { A10, A11, A12, } \\
\text { A13, A14, A15, } \\
\text { A17, A18, A20, } \\
\text { A22, A25, A28 }\end{array}$ \\
\hline $\begin{array}{l}0 \text { ser humano } \\
\text { altera o meio } \\
\text { ambiente }\end{array}$ & $\begin{array}{l}\text { Nesta categoria o meio ambiente } \\
\text { assume um caráter critico, aliado a } \\
\text { sociedade que interfere no mesmo, } \\
\text { alterando as relações sociais, } \\
\text { politicas, econômicas e culturais. }\end{array}$ & 8 & 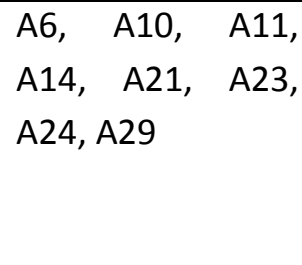 \\
\hline
\end{tabular}

Fonte: Autores, 2018

A primeira categoria trás a ciência como um meio para sanar os problemas encontrados na sociedade. Muitas vezes o homem estabelece uma relação de exploração com a natureza e se utiliza para suprir suas necessidades de forma. Este fato também foi evidenciado na segunda e 
terceira categoria, onde os alunos percebem em questões diferentes como o ambiente é modificado pelo homem, a sociedade e os demais aspectos. Dessa forma, as categorias foram discutidas em conjunto, uma vez que as três estão ligadas entre si.

A utilização de espaços para realização de atividades que vai de produção de bens a outros serviços e funções visa atender uma demanda da população, que procura cada vez mais por soluções e inovações tecnológicas para suprir não só suas necessidades, mas também realizações pessoais. Está exigência gera uma crise ecologia que não se restringe a algumas cidades ou países, abrange todo o Planeta, não só no aspecto ecológico, mas também no social, provocando dicotomias em vários segmentos da sociedade.

Tudo isso é permeado pela qualidade do meio ambiente, uma vez que nossas relações com o mesmo não são apenas biológicas e físicas, mas também sociais. Mas nem sempre o ambiente é pensando assim. Segundo Adams (2005) muitas vezes é comum resumir o meio ambiente apenas em problemas ambientais, a preservação da natureza, diminuição do lixo, a proteção dos animais, etc., que é uma questão originada da dicotomia que é feita entre o ser humano e a natureza, como se a natureza estivesse a serviço do homem.

Estas questões podem e devem ser discutidas através da educação ambiental que é pensada e categorizada em diferentes vertentes de acordo com as vivências, influências e contextos. Quando o ambiente é pensado apenas em seu sentido biológico, a educação ambiental assume um caráter naturalista, reforçando a vertente da educação ambiental conservacionista, onde as questões sociais não são pensadas nem refletidas, por outro lado, outra vertente da educação ambiental é a chamada educação ambiental crítica, que é uma práxis social e tem objetivo de emancipação do sujeito e buscando a sua transformação por meio da compreensão da realidade de maneira completa, não fragmentada (LOUREIRO; TOZONI-REIS, 2007).

Desta forma o processo educativo ambiental precisa ser pensando dentro desta perspectiva, quebrando assim o conceito enraizado de ambiente que não considera seu caráter social e histórico, não resumindo apenas a concepção biológica.

$\mathrm{Na}$ educação, sua abordagem teve maior influência com Paulo Freire, que destaca a educação em uma concepção dialética, como atividade social ligada aos processos de transformação de uma sociedade capitalista e alienada.

Considerando então que a educação ambiental crítica visa à formação de cidadãos críticos, reflexivos e transformadores é preciso que estas questões sejam pensadas na formação inicial de professores, juntamente com a importância de uma formação histórico crítica, para que o sujeito consiga se entender para além do ambiente ao seu serviço, mas sim para o contexto, os problemas ambientais além da biologia pura ele precisa ter artifícios, argumentos, e até mesmo a pratica do olhar de uma maneira crítica, reflexiva para as situações, pensando nos problemas ambientais como os problemas que causam desequilíbrio no ambiente como um todo, não apenas pensar no lixo como lixo, mas pensar no lixo como consumismo.

Durante o filme: "Sonhos Tropicais" é possível perceber como estas questões ligadas ao meio ambiente se fazem presentes desatacando como demais aspectos como a politica, cultura, ciência, economia, mídia, e sociedade influenciam para determinar o contexto do ambiente. Este mesmo contexto pode ser entendido através da educação, quando a mesma é pensando como uma prática social, visando à formação emancipatória do sujeito.

Neste sentido é importante conhecer e compreender a relação do meio ambiente com a 
ciência que se utilizada da tecnologia para reger e determinar as questões na sociedade.

A partir de um movimento iniciado na Europa e EUA, que promoveu a participação democrática das discussões relacionadas à Ciência e Tecnologia (C\&T), foi possível uma melhor compreensão destes termos, que poderiam gerar impactos positivos e negativos na vida das pessoas.

No decorrer dos anos, a ciência e a tecnologia tiveram participação fundamental na sociedade, de modo que, diversos fatores contribuíram para o desenvolvimento da nossa atual conjuntura social.

A orientação quanto à CTS na educação em ciências, melhora a criatividade e a compreensão dos conceitos científicos e contribui para o desenvolvimento do aluno na aprendizagem da ciência, mas também alerta para a necessidade de um programa de formação para docentes, no qual estes sejam capazes de proporcionar bases teóricas e aplicação prática com enfoque em CTS.

Para Paulo Freire (1993), a ciência e a tecnologia são forças que podem manter a ordem opressora, servindo ate para manipular e esmagar. Logo, a ciência e a tecnologia não podem ser consideradas somente pelo ponto de vista positivo, caracterizada pela busca de desenvolvimento tecnológico, de modo a desprezar os desvios que ocorrem.

Para que o estudo em CTS seja significativo, é importante que o profissional mediador tenha uma formação sólida e seja capaz de estimular reflexões relacionadas às implicações destes estudos para a sociedade e vice-versa, proporcionando um ativo exercício da cidadania.

Conforme Medina (2003), a área de Ciência, Tecnologia e Sociedade (CTS) surgiu após a Segunda Guerra Mundial e início da Guerra Fria, onde a pesquisa científica possuía característica organizacional estatal e militar. Simultaneamente, o campo se consolidava em uma visão positivista de Ciência e Tecnologia que permanece até atualmente.

Os principais países capitalistas, a partir da metade do século $X X$, começaram a questionar o desenvolvimento científico, tecnológico e econômico, uma vez que não havia preocupação com o desenvolvimento do bem estar social (AULER E BAZZO, 2001).

No final da década de 1960, a visão positivista foi alvo de questionamentos e movimentos populares nos países mais avançados, além do modelo de desenvolvimento, a academia europeia também foi alvo de críticas quanto à abordagem do mesmo tema.

A junção dos dois movimentos permitiu que a Ciência e Tecnologia (C\&T) recebesse um olhar mais crítico quanto à degradação ambiental e desenvolvimento científico tecnológico para a guerra.

Quanto à provocação da politização sobre C\&T, Luján Lópes et al. (1996) destacam a falta de um questionamento da época sobre a gestão tecnocrática dos assuntos sociais, políticos e econômicos, apontando consequências negativas e reivindicando novos métodos de C\&T, tendo a participação da sociedade. Nessa perspectiva, as decisões tomadas nessa área teriam caráter democrático, onde a sociedade também poderia ter controle sobre a atividade científico-tecnológica, tornando-se tema para debate político e emergindo o movimento de Ciência, Tecnologia e Sociedade (CTS).

Ao longo dos anos, o movimento de CTS adquiriu caráter acadêmico, tendo como base estudos com enfoque no desenvolvimento da teorização e métodos de indagação e análise em níveis complexos (ESTEVES \& MOURA, 2009). A formação de especialistas tornou-se mais importante 
que a militância, tendo como meta a busca da compreensão da dimensão social da ciência e tecnologia,

Atualmente, há o compartilhamento de ideias, chamado de "silogismo CTS", onde o desenvolvimento científico-tecnológico é compreendido como um processo social abrangendo fatores culturais, políticos e econômicos. Considera-se que a tecnologia é a ciência aplicada e neutra, e há a necessidade de construção de bases educativas e mecanismos institucionais para a promoção da participação social e pública em CTS.

O entendimento de tecnologia como ciência aplicada contribuiu para a concepção pedagógica da educação tecnocientífica, onde os Estudos de Ciência, Tecnologia e Sociedade (ECTS), contribuem para a melhor e maior compreensão acerca das implicações da C\&T.

No Brasil a partir de 1980 a Educação Tecnológica vem se direcionando para o enfoque CTS, o qual vem sendo muito difundido, principalmente no ensino de ciências, segundo PINHEIRO et al. (2007). Já os textos que abordam esta temática se acentuaram no início da década de 1990, focando principalmente a área de ensino de ciência e tecnologia.

No entanto, para AULER (2007) o tema CTS ainda se encontra em emergência, com poucas iniciativas, às quais muitas vezes isoladas e ausentes de programas institucionais. $E$, também paro estudo CTS por ser muito recente, emana abordagens e sentidos diferentes para os envolvidos no tema.

O que se pretende com esse estudo segundo CHRISPINO et al. (2013), é que seja construído conhecimentos das implicações tecnocientíficas para o contexto social, proporcionando assim a possibilidade de participação democrática da sociedade na escolha dos seus rumos, não ficando, assim, à mercê das decisões tomadas pelos tecnocratas ou dos que pensam que a ciência e a tecnologia não possuem interesses envolvidos e são neutras.

Ao se assumir criticamente o objetivo desse movimento, há indicativos de que além de proporcionar uma participação mais qualificada da sociedade através de conhecimentos e informações construídas, se faz necessário também, a construção de uma cultura de participação, que segundo implicará no questionamento dos efeitos da evolução e utilização da ciência e tecnologia em seu entorno, percebendo que certas atitudes estão muitas vezes atreladas aos interesses dominantes.

A educação tecnológica no ensino médio para Santos (2007), não deve se limitar apenas em fornecer meros conhecimentos técnicos do funcionamento de certos artefatos da tecnologia, onde prepara o cidadão apenas para manusear determinadas ferramentas tecnológicas ou para habilitar o docente às novas tecnologias. Esses conhecimentos são de grande relevância, porém é alienante restringir essa educação ao uso e compreensão do funcionamento das tecnologias, pois apenas contribui para a continuidade do processo de dominação do homem aos ideais de lucro a qualquer preço, prejudicando assim cada vez mais a busca por um desenvolvimento sustentável.

Sendo o campo educativo um dos principais focos de investigação e ação social do movimento CTS há mais de trinta anos, percebe que ele traz essa preocupação com a renovação na estrutura curricular dos conteúdos, buscando colocar ciência e tecnologia em novas abordagens vinculadas ao contexto social. 
Assim, Auler (2007), defende a necessidade de mudanças no campo curricular, mudanças profundas, mais sensíveis ao entorno, com abertura a temas aos problemas que estão ligados ao componente científico-tecnológico, dando enfoque a temas/problemas sociais relevantes. Para Santos (2007), os currículos de ensino em ciências, por apresentarem o propósito voltado para a cidadania, poderiam implicitamente ser considerados como sempre presentes na ênfase em CTS, porém, das diversas versões dos Parâmetros Curriculares Nacionais do ensino fundamental e médio essas recomendações só foram incorporadas mais explicitamente a esses documentos legais nos últimos dez anos.

Os Parâmetros Curriculares Nacionais (PCNs) difundem a ideia de levar para sala de aula como uma maneira de Educação Tecnológica, tanto no Ensino Fundamental quanto no Ensino Médio, um debate a cerca das relações existentes entre ciência, tecnologia e sociedade construindo com o aluno conhecimentos da origem e do uso que se faz dos artefatos e a sua implicação na sociedade atual, desvinculando ao pensamento de apenas confeccionar artefatos.

Os objetivos propostos na LDB também se relacionam com o movimento CTS, em seu artigo 36 a LDB ressalta que o Ensino Médio deve proporcionar ao estudante, além do acesso aos conhecimentos sobre ciência e tecnologia, o entendimento sobre a formação desses processos, bem como sua implicação, consequências e as atitudes necessárias ao cidadão perante os problemas.

Assim é necessário que compreender o contexto historio para entender os processos que influenciam e modificam a sociedade, Brandão (2009) afirma que para a educação ambiental seja construída de forma eficaz esse contexto precisa ser compreendido, além de também destacar que é necessário que este processo seja continuo e que envolva não só a escola como também a comunidade.

Tristão (2002) complementa com os quatro desafios da Educação ambiental:

1) "enfrentar a multiplicidade de visões", isto é, o educador precisa fazer conexões, identificar e compreender todas as interpretações relacionadas ao meio ambiente;

2) "superar a visão do especialista", promovendo a ruptura da visão de especialidades, de práticas disciplinares;

3) "superar a pedagogia das certezas", o que remete a pensar nos riscos produzidos e nas incertezas científicas;

4) "superar a lógica da exclusão", o qual refere-se à necessidade de superação das desigualdades sociais. (TRISTÃO, 2002)

\section{CONSIDERAÇÕES FINAIS}

A formação inicial de professores precisa ser repensada, neste sentido é necessário que as práticas pedagógicas dialoguem com os conteúdos, uma vez que se busca formar cidadãos críticos e reflexivos para compreender e entender o sistema onde estão inseridos e assim transforma-lo. Dentro deste contexto, a educação ambiental quando pensada em um viés critico se mostra como uma boa oportunidade para auxiliar na compreensão do ambiente e nos fatores que influenciam o mesmo, juntamente com o cinema que permite que o aluno possa compreender e discutir e problematizar através de filmes, curta metragem entre outros que mostram a realidade da sociedade, além de trazer elementos que permitem discutir os 
fatores sociais, políticos, econômicos, éticos, científicos que influenciaram para moldar a atual sociedade.

Sendo assim, a partir do trabalho é possível perceber como estas questões podem contribuir para a formação inicial de professores, além de também contribuir para que a educação ambiental seja discutida em um viés critico e assim buscar a formação de cidadãos críticos e transformadores e como o cinema pode auxiliar para esse assunto seja trabalho, como também auxilia para mostrar a interdisciplinaridade dos conteúdos.

\section{REFERÊNCIAS BIBLIOGRÁFICAS}

ADAMS, Berenice Gehlen. O que é Educação Ambiental? Publicado no website do Projeto Apoema - Educação Ambiental, 2005.

AULER, Décio. Enfoque Ciência-Tecnologia-Sociedade: pressupostos para o contexto brasileiro. Ciência \& Ensino (ISSN 1980-8631), v. 1, 2008.

BRANDÃO, Carlos Rodrigues. Identidade da Educação Ambiental Brasileira. Brasília, 2004.

CABRERA, Julio. $\mathbf{O}$ cinema pensa: uma introdução à filosofia através dos filmes. Editora Rocco, 2006.

CÂNDIDO, Tatiane Cristina Barbosa; FESTOZO, Marina Battistetti; JUNIOR, Antonio Fernandes Nascimento. "SONHOS TROPICAIS": uma leitura do cinema para a educação ambiental crítica.

CHRISPINO, Alvaro et al. A área CTS no Brasil vista como rede social: onde aprendemos?. Ciência \& Educação (Bauru), v. 19, n. 2, 2013.

CUTCLIFFE, Stephen H. Ideas, máquinas y valores: Los estudios de Ciencia, Tecnología y Sociedad. Anthropos Editorial, 2004

DE ARAÚJO ESTEVES, Simone; DE MOURA, Dácio Guimarães. Percepções acerca da ciência e da tecnologia de alunos de licenciatura em ciências biológicas tendo em vista os estudos ciência-tecnologia-sociedade (cts) the perceptions about science and technology of students of biological sciences pedagogy course in view of studies of the.

DE SOUZA MINAYO, María C. O desafio do conhecimento. Pesquisa qualitativa em saúde. 2008.

DOS SANTOS, Wildson Luiz Pereira. Contextualização no ensino de ciências por meio de temas CTS em uma perspectiva crítica. Ciência \& Ensino (ISSN 1980-8631), v. 1, 2008

FREIRE, Paulo. Pedagogia da Esperança: Um reencontro com a pedagogia do oprimido. Rio de Janeiro: Paz e Terra, 1993..

LUJÁN LÓPES, J. L. et al. Ciencia, Tecnología y Sociedad: una introducción al estudio social de la ciencia y la tecnología. Madrid: Tecnos, 1996.

LOUREIRO, Carlos Fredetico. Pesquisa-ação participante e educação ambiental: uma abordagem dialética e emancipatória. In: Tozoni- Reis, Marília Freitas de Campos, org. A pesquisa-ação-participativa em educação ambiental: reflexões teóricas/ Organização de Marília Freitas de Campos. - São Paulo, 2007.

MACIEL PINHEIRO, Nilcéia Aparecida; MONTEIRO CASTILHO FOGGIATTO SILVEIRA, Rosemari; BAZZO, Walter Antonio. Ciência, tecnologia e sociedade: a relevância do enfoque CTS para o contexto do ensino médio. Ciência \& Educação (Bauru), v. 13, n. 1, 2007.

TOZONI- REIS, Marília Freitas Campos, org. A pesquisa-ação-participativa em educação ambiental: reflexões teóricas/ Organização de Marília Freitas de Campos. - São Paulo, 2007

TRISTÃO, Martha. As dimensões e os desafios da educação ambiental na sociedade do conhecimento. In: 
RUSHEINSKY, A. (Org.). Educação ambiental: abordagens múltiplas. Porto Alegre: Artmed, 2002.

APOIO

CAPES E FAPEMIG 